\title{
Acute kidney injury after hepatic ischemia and reperfusion injury in mice
}

\author{
H Thomas Lee ${ }^{1}$, Sang W Park ${ }^{1}$, Mihwa Kim ${ }^{1}$ and Vivette D D'Agati ${ }^{2}$
}

Hepatic ischemia reperfusion (IR) is the leading cause of acute liver failure (ALF) during the perioperative period and patients with ALF frequently develop acute kidney injury (AKI). There is no effective therapy for AKI associated with ALF because pathomechanisms are incompletely characterized, in part due to the lack of an animal model. In this study, we characterize a novel murine model of AKI following hepatic IR. Mice subjected to $\sim 70 \%$ liver IR not only developed acute liver dysfunction, but also developed severe AKI $24 \mathrm{~h}$ after liver injury. Mice subjected to liver IR developed histological changes of acute tubular injury including focal proximal tubular cell necrosis involving the S3 segment, cortical tubular ectasia, focal tubular simplification and granular bile/heme cast formation. In addition, there was focal interstitial edema and hyperplasia of the juxtaglomerular apparatus. Inflammatory changes in the kidney after hepatic IR included neutrophil infiltration of the interstitium and upregulation of several proinflammatory mRNAs (tumor necrosis factor- $\alpha$, keratinocyte-derived cytokine, monocyte chemotactic protein-1, macrophage inflammatory protein-2, intercellular adhesion molecule-1). In addition, marked renal endothelial cell apoptosis was detected involving peritubular interstitial capillaries, accompanied by increased renal vascular permeability. Finally, there was severe disruption of renal proximal tubule epithelial filamentous-actin. Our results show that AKI rapidly and reproducibly develops in mice after hepatic IR and is characterized by renal tubular necrosis, inflammatory changes and interstitial capillary endothelial apoptosis. Our murine model of AKI after liver injury closely mimics human AKI associated with ALF and may be useful in delineating the mechanisms and potential therapies for this common clinical condition.

Laboratory Investigation (2009) 89, 196-208; doi:10.1038/labinvest.2008.124; published online 15 December 2008

KEYWORDS: acute renal failure; apoptosis; endothelium; inflammation; necrosis

Hepatic ischemia reperfusion (IR) injury is a major clinical problem during the perioperative period. Hepatic IR injury is a major cause of acute liver failure (ALF) and is a frequent complication of major hepatic resection, liver transplantation or septic shock. ${ }^{1-3}$ Acute kidney injury (AKI) occurs frequently in patients with ALF and is a serious clinical problem during the perioperative period. ${ }^{4,5}$ For example, the incidence of AKI in patients with ALF ranges from 40 to $85 \%$ depending on the diagnostic criteria and etiology., In addition, AKI is a common complication after orthotopic liver transplantation and it exponentially increases patient mortality. ${ }^{4}$ Unfortunately, the pathophysiology of AKI associated with ALF is poorly understood in part due to a lack of diagnostic histological changes or an adequate animal model for this critical clinical syndrome. Moreover, development of AKI after liver injury in mice has never been described in detail.
Previous animal models for AKI associated with liver failure include carbon tetrachloride $\left(\mathrm{CCl}_{4}\right)$ injection after bile duct ligation in mice ${ }^{7}$ and partial hepatic IR in rats. ${ }^{8}$ The $\mathrm{CCl}_{4}$ injection model is limited by the chronic nature of the protocol requiring several ${ }^{8-12}$ weeks (whereas human renal failure associated with ALF can develop acutely). The rat model of AKI after liver IR is limited by the modest nature of renal dysfunction after liver IR injury, which, therefore, fails to mimic the severity of human disease. ${ }^{8,9}$

In this study, we tested the hypothesis that mice subjected to severe liver IR develop AKI resembling human AKI associated with ALF. We demonstrate that mice subjected to hepatic IR develop AKI in less than $24 \mathrm{~h}$ characterized by proximal tubular necrosis and inflammation. Moreover, renal peritubular endothelial cell apoptosis, peritubular/interstitial neutrophil infiltration, JGA hyperplasia as well as marked

\footnotetext{
${ }^{1}$ Department of Anesthesiology, College of Physicians and Surgeons of Columbia University, New York, NY, USA and ${ }^{2}$ Department of Pathology, College of Physicians and Surgeons of Columbia University, New York, NY, USA

Correspondence: Dr HT Lee, MD, PhD, Department of Anesthesiology, Anesthesiology Research Laboratories, Columbia University, P\&S Box 46 (PH-5), 630 West 168 th Street, New York, NY 10032-3784, USA.

E-mail: t1128@columbia.edu
}

Received 26 August 2008; revised 3 October 2008; accepted 24 October 2008 
disruptions of the kidney tubular actin cytoskeletal architecture were observed. Our results show that mice subjected to liver IR develop AKI rapidly, closely mimicking the time course of this complication in humans.

\section{MATERIALS AND METHODS}

\section{Murine Model of Hepatic IR}

After Columbia University IACUC approval, male C57BL/6 mice (25-30 g; Harlan, Indianapolis, IN, USA) were anesthetized with intraperitoneal pentobarbital, $50 \mathrm{mg} / \mathrm{kg}$ or to effect. Mice were placed under a heating lamp and on a $37^{\circ} \mathrm{C}$ heating pad. After a midline laparotomy and intraperitoneal application of $20 \mathrm{U}$ heparin, left lateral and median lobes of the liver were subjected to $60 \mathrm{~min}$ of ischemia, with a microaneurysm clip occluding the hepatic triad above the bifurcation. This method of partial hepatic ischemia results in a segmental $(\sim 70 \%)$ hepatic ischemia but spares the right lobe of the liver and prevents mesenteric venous congestion by allowing portal decompression through the right and caudate lobes of the liver. ${ }^{10,11}$ Preliminary studies showed that 30,60 or $90 \mathrm{~min}$ of liver ischemia causes mild, moderate or severe liver injury, respectively. The liver was kept moist with gauze soaked in $0.9 \%$ normal saline. The body temperature was monitored by an infrared temperature sensor (Linear Laboratories, Fremont, CA, USA) and maintained at $37^{\circ} \mathrm{C}$ using a heating lamp and a heating pad. After $60 \mathrm{~min}$, the liver was reperfused and the wound closed. Sham-operated mice were subjected to laparotomy and identical liver manipulations without the vascular occlusion. Twenty-four hours after reperfusion, the liver tissue subjected to IR and both kidneys were collected to measure necrosis, neutrophil infiltration (with immunohistochemistry) and apoptosis (with terminal deoxynucleotidyl transferasemediated dUTP nick-end labeling staining). In some mice, liver and kidneys were collected $4 \mathrm{~h}$ after reperfusion to detect renal inflammation by RT-PCR for proinflammatory cytokine mRNAs. We also collected plasma for the measurement of alanine aminotransferase (ALT) and creatinine $(\mathrm{Cr}) 4$ and $24 \mathrm{~h}$ after reperfusion.

\section{Assessment of Liver and Kidney Dysfunction}

Plasma ALT was measured by using a Prep-Profile II kit and a VetScan VS2 Point-of-Care Analyzer (Union City, CA, USA) and expressed as Units/liter (U/l). Renal dysfunction after liver IR injury was assessed by measurement of plasma creatinine by a colorimetric method based on the Jaffe reaction. ${ }^{12}$

\section{Histology and Quantification of Hepatic and Renal Injury after Hepatic IR Injury}

Twenty-four hours after reperfusion, the liver tissue subjected to IR and both kidneys were collected. For histological preparations, explanted murine livers or kidneys were fixed in $10 \%$ formalin solution overnight. After automated dehydration through a graded alcohol series, transverse liver slices

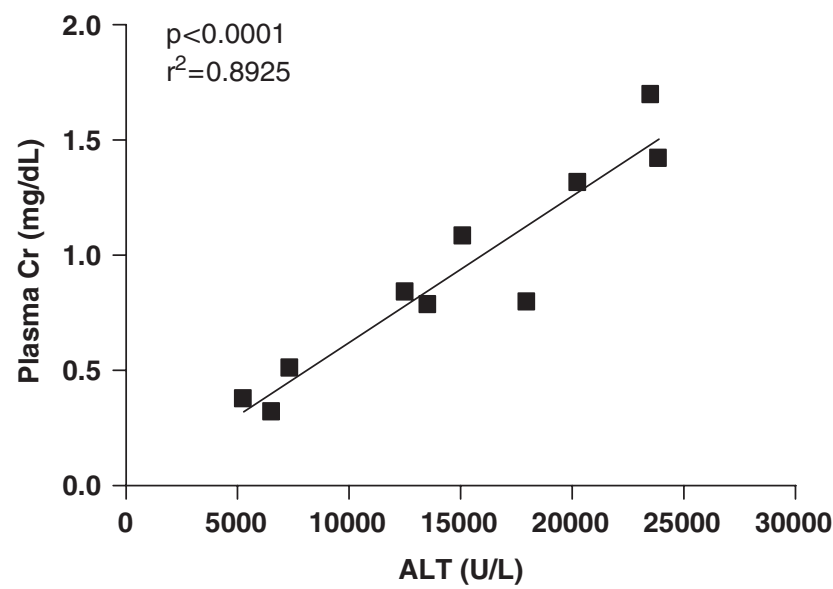

Figure 1 Correlation between plasma ALT and creatinine $(\mathrm{Cr})$ values $\left(P<0.0001\right.$ and $\left.r^{2}=0.8925\right)$. C57BL/6 mice were subjected to 60 min liver ischemia and $24 \mathrm{~h}$ reperfusion, and plasma collected for ALT and creatinine assays $(N=10)$.

were embedded in paraffin, sectioned at $4 \mu \mathrm{m}$, and stained with hematoxylin-eosin (H\&E). To quantify the degree (\%) of hepatic necrosis, liver $\mathrm{H} \& \mathrm{E}$ sections were digitally photographed and the percent of necrotic area was quantified with NIH IMAGE (Image-J, 1.37v) software by a person who was unaware of the treatment each sample received. Renal H\&E sections were evaluated for renal proximal tubule necrosis and apoptosis, endothelial cell apoptosis, tubular simplification, juxtaglomerular apparatus hypertrophy and cell number by an experienced renal pathologist (VDD) who was blinded to the treatment each animal had received.

\section{Assessment of Renal Inflammation}

Kidney inflammation after hepatic ischemia was determined by the detection of neutrophil infiltration by immunohistochemistry $24 \mathrm{~h}$ after hepatic IR as described previously ${ }^{13-15}$ and by measuring mRNA encoding markers of inflammation, including keratinocyte derived cytokine (KC), intercellular adhesion molecule-1 (ICAM-1), monocyte chemoattractive protein-1 (MCP-1), macrophage inflammatory protein-2 (MIP-2), and tumor necrosis factoralpha (TNF- $\alpha$ ) $4 \mathrm{~h}$ after liver IR. Both semiquantitative $\mathrm{e}^{13-15}$ and quantitative real-time RT-PCR (Q-RT-PCR) were performed. Q-RT-PCR was performed with the MyiQ Real Time Detection System (Bio-Rad, Hercules, CA, USA) using SYBR Green I Brilliant Mastermix (Stratagene, La Jolla, CA, USA). The cDNA template was synthesized using Omniscript Reverse Transcriptase and oligo-dT primer (Qiagen, Valencia, CA, USA). Specificity of the amplification was checked by melting curve analysis and by agarose gel electrophoresis. All reactions were performed in duplicate with appropriate negative controls. The $C_{\mathrm{t}}$ values were determined by using Mx3000P software. Values were normalized for GAPDH mRNA and relative expression of proinflammatory mRNA was calculated with the $\Delta \Delta C_{\mathrm{t}}$ method. 
a

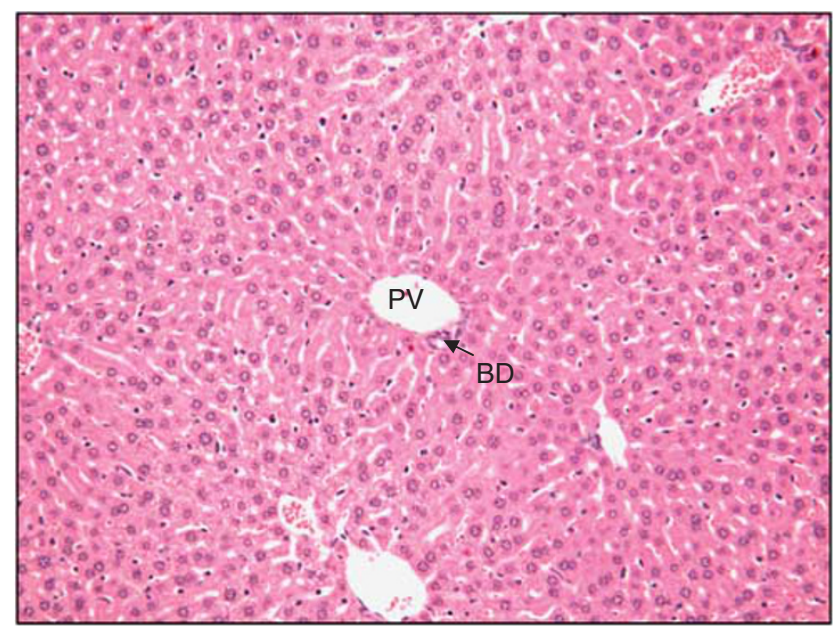

b

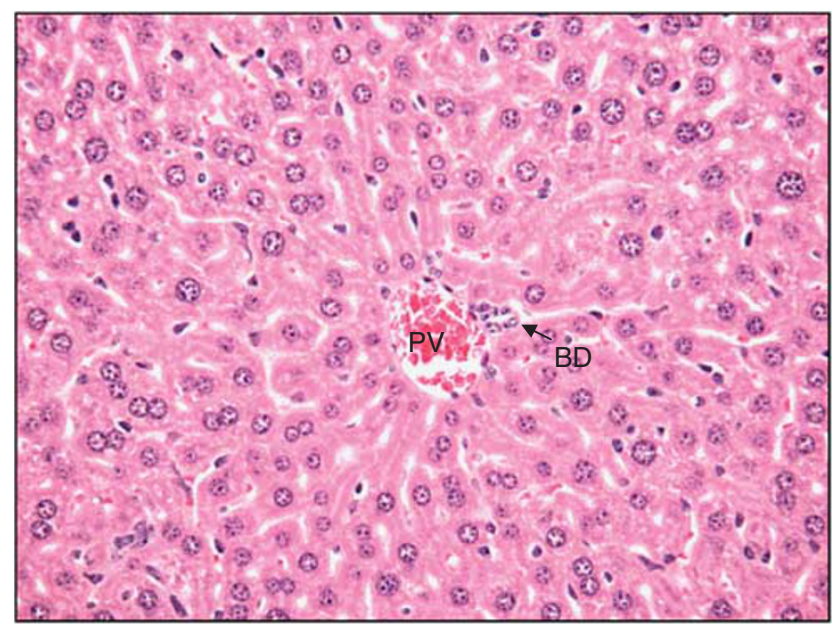

c

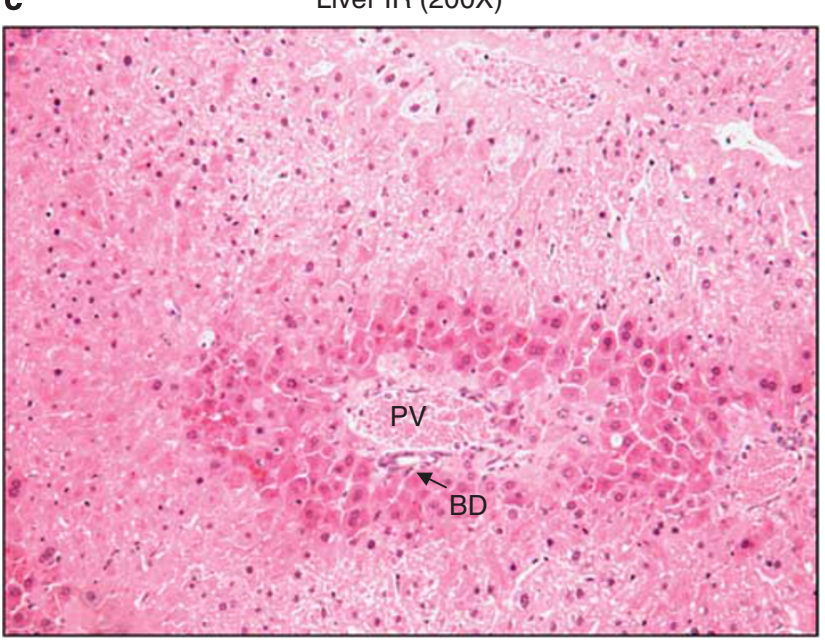

d

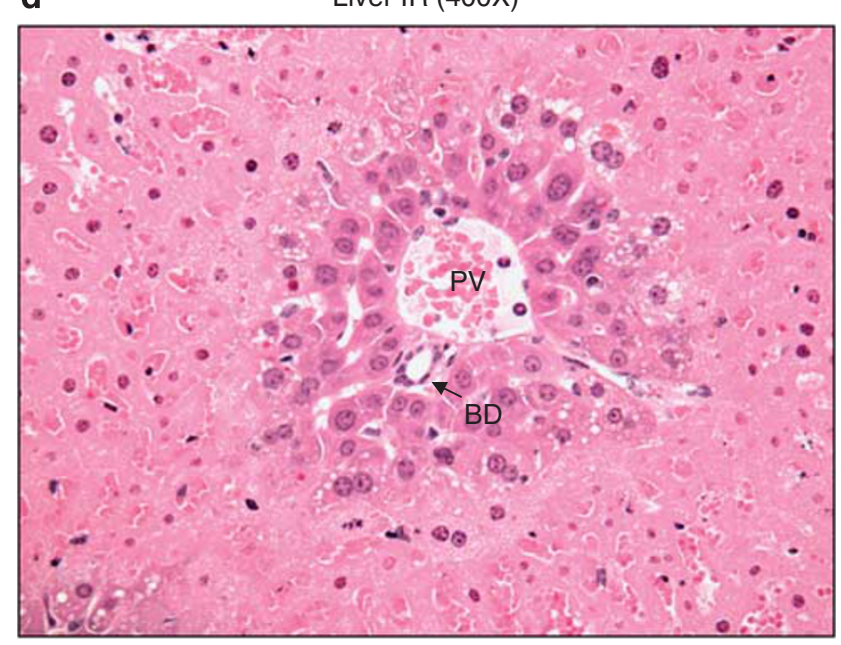

Figure 2 Representative photomicrographs of five experiments (hematoxylin and eosin staining, magnification $\times 200$ (a and $\mathbf{c}$ ) and $\times 400$ (b and d) of mice subjected to sham operation or to liver IR injury. Sham-operated animals show normal-appearing hepatocyte parenchyma (a and $\mathbf{b})$. Following liver IR, there is severe hepatocyte necrosis and loss of normal liver architecture with some sparing of the hepatocytes near the portal triad. PV $=$ portal vein. $\mathrm{BD}=$ bile duct.

\section{Detection of Renal Apoptosis with In Situ Terminal Deoxynucleotidyl Transferase Biotin-dUTP Nick-End Labeling Assay}

Twenty-four hours after reperfusion, the liver tissue subjected to IR and both kidneys were collected. We used in situ terminal deoxynucleotidyl transferase biotin-dUTP nick-end labeling (TUNEL) staining to detect DNA fragmentation in apoptosis as described previously. ${ }^{16,17}$

\section{Filamentous-Actin Staining of Liver and Kidney Sections after Liver IR Injury}

Twenty-four hours after reperfusion, the liver tissue subjected to IR and both kidneys were collected. As breakdown of filamentous (F)-actin occurs early after IR, we visualized the F-actin cytoskeleton by staining with phalloidin as an early index of liver as well as renal injury. ${ }^{18,19}$
We visualized the F-actin cytoskeleton by staining with phalloidin. Twenty-four hours after liver IR, liver and kidney tissue were embedded in Tissue-Tek oxytetracycline compound (Fisher Scientific, Pittsburgh, PA, USA) and cut into $5 \mu \mathrm{m}$ sections. To reduce background staining, the sections were incubated in 1\% FBS dissolved in PBS for $10 \mathrm{~min}$ at room temperature. The sections were then stained with Alexafluor 594 (Red)-labeled phalloidin (Invitrogen, Carlsbad, CA, USA) for $30 \mathrm{~min}$ at $37^{\circ} \mathrm{C}$ in a humidified chamber in the dark. Sections were then washed twice in PBS and mounted with Vectashield (Vector Laboratories, Burlingame, CA, USA). F-actin images were visualized with an Olympus IX81 epifluorescence microscope (Tokyo, Japan) and captured and stored using SlideBook 4.2 software (Intelligent Imaging Innovations Inc., Denver, CO, USA) on a personal computer. 

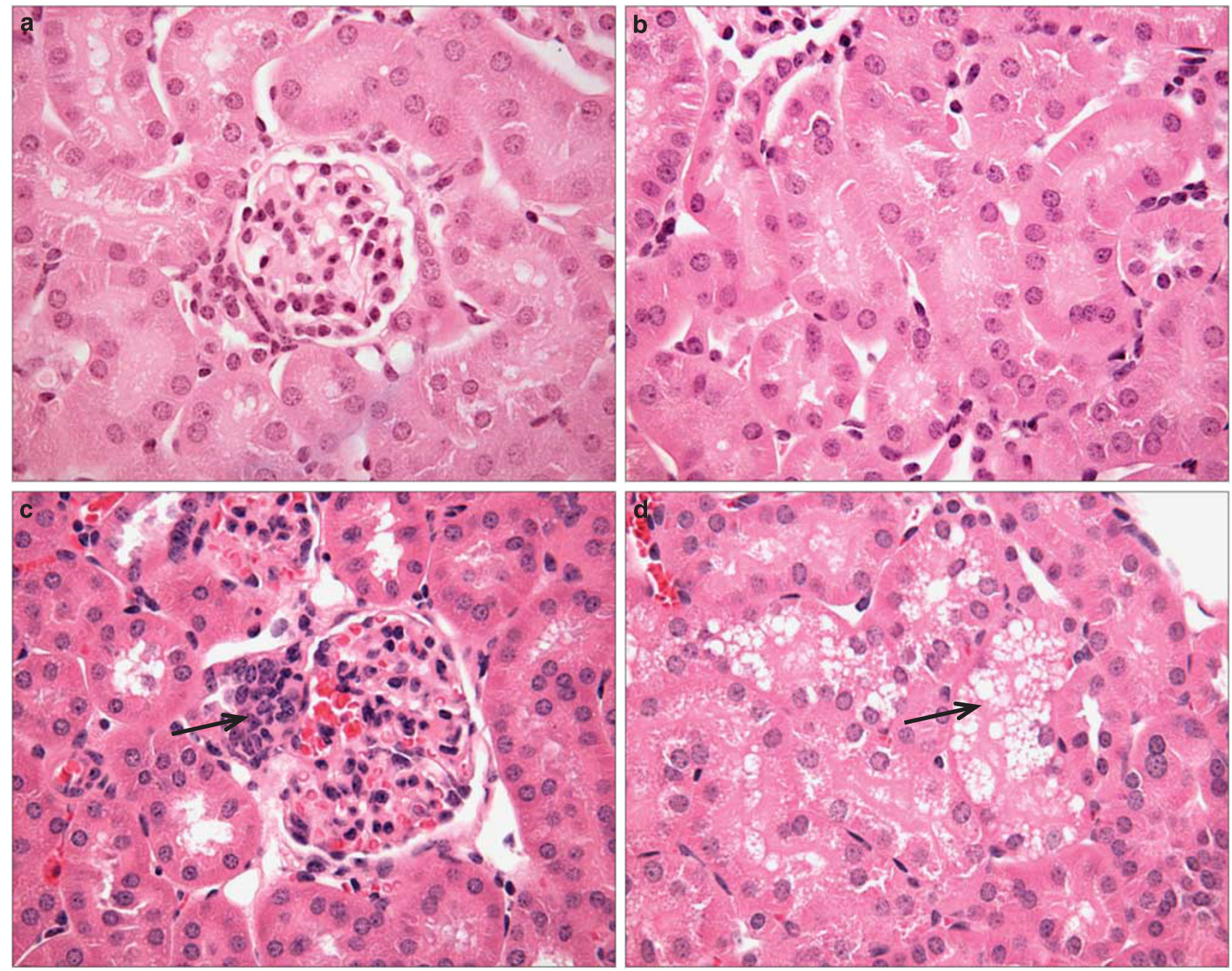

Figure 3 Representative photomicrographs of six experiments (hematoxylin and eosin staining, magnification $\times 600$ ) of mice subjected to sham operation or to liver IR injury. Sham-operated animals show normal-appearing glomeruli (a) and tubules (b). Following liver IR, many glomeruli display prominent hyperplasia of the juxtaglomerular apparatus (arrow) located at the glomerular hilus (c). There is focal coarse clear cytoplasmic vacuolization (arrow) of proximal tubular epithelial cells (d). Some cortical tubular cells display acute epithelial injury with cellular condensation and cytoplasmic hypereosinophilia (long arrow) and shrunken, hyperchromatic nuclei (insert expanded; e). There is focal apoptosis of interstitial capillary endothelial cells (insert expanded) with marked vascular stasis within the interstitial capillary lumina (thick arrow; $\mathbf{f}, \mathbf{g}$ ). We also observed focal tubular dilatation and simplification with intraluminal shedding of cytoplasmic debris and formation of granular eosinophilic casts (arrow; $\mathbf{h}$ ).

\section{Analysis of Liver and Kidney Vascular Permeability}

Twenty-four hours after reperfusion, the liver tissue subjected to IR and both kidneys were collected. Changes in liver and kidney vascular permeability were assessed by quantitating extravasations of Evans blue dye (EBD) into the tissue as described by Awad et $a l^{20}$ with some modifications. Briefly, $2 \%$ EBD (Sigma Biosciences, St Louis, MO, USA) was administered at a dose of $20 \mathrm{mg} / \mathrm{kg}$ i.v. $24 \mathrm{~h}$ after liver injury. One hour later, mice were killed and perfused through the heart with PBS and EDTA with $10 \mathrm{cc}$ cold saline with heparin $(100 \mathrm{U} / \mathrm{ml})$. Liver and kidneys were then removed, allowed to dry overnight at $60^{\circ} \mathrm{C}$, and the dry weights were determined. EBD was extracted in formamide $(20 \mathrm{ml} / \mathrm{g}$ dry tissue; Sigma
Biosciences), homogenized, and incubated at $60^{\circ} \mathrm{C}$ overnight. Homogenized samples were centrifuged at $5000 \mathrm{~g}$ for $30 \mathrm{~min}$ and the supernatants were measured at 620 and $740 \mathrm{~nm}$ in a spectrophotometer. The extravasated EBD concentration was calculated against a standard curve and the data expressed as micrograms of EBD per gram of dry tissue weight.

\section{Protein Determination}

Protein contents were determined with a bicinchoninic acid protein assay kit (Pierce Chemical Co., Rockford, IL, USA), using BSA as a standard. 

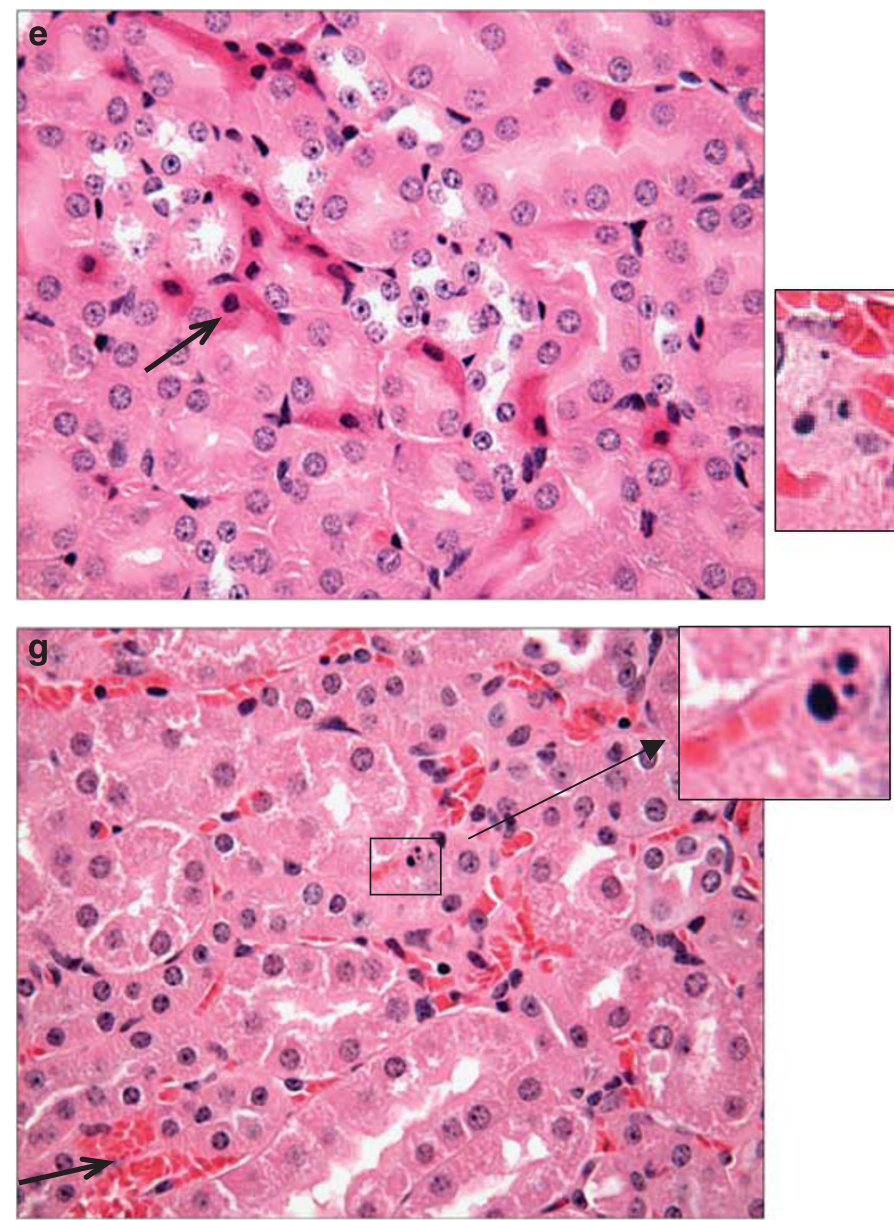
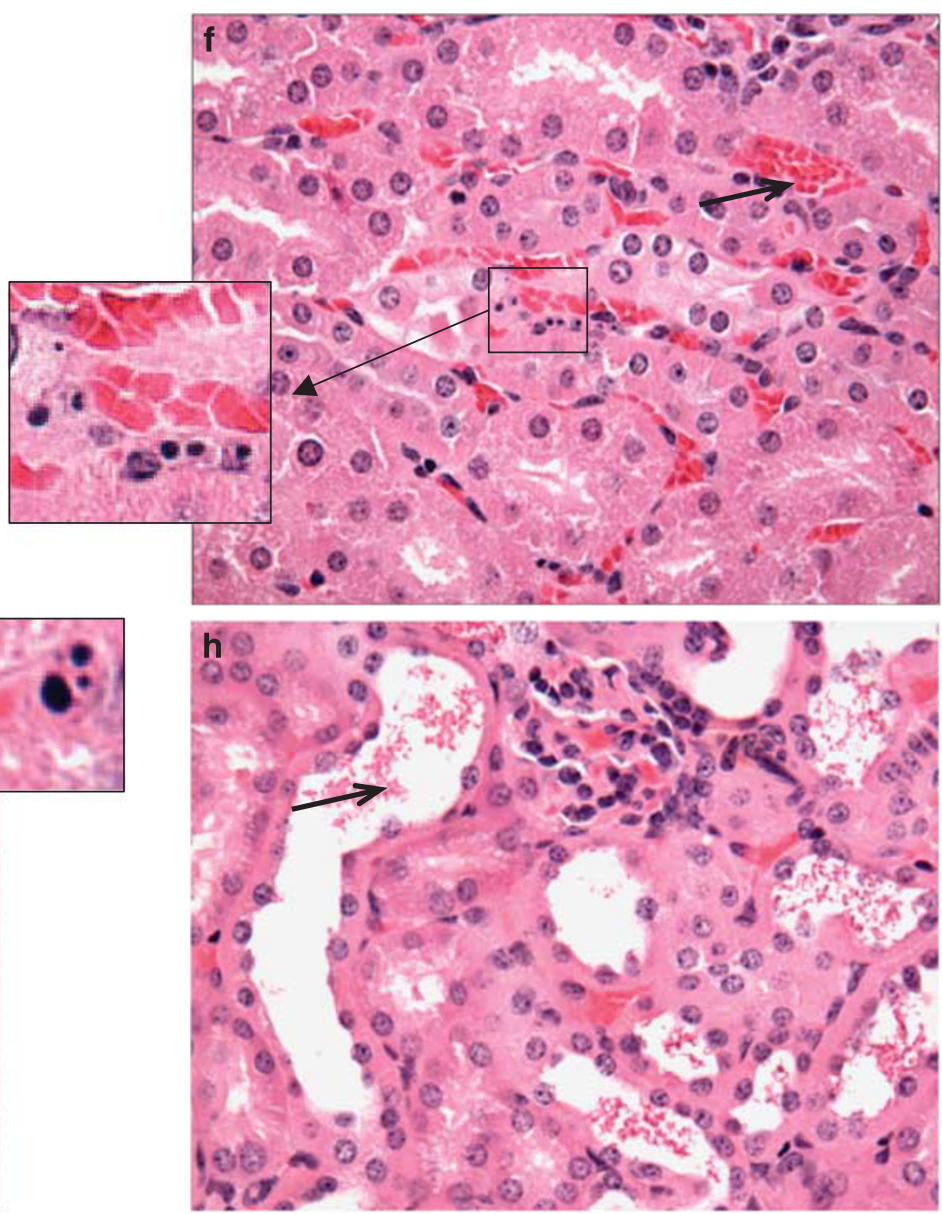

Figure 3 Continued.

\section{Statistical Analyses}

The data were analyzed with Student's $t$-test when comparing means between two groups or with one-way analysis of variance plus Tukey's post hoc multiple comparison test to compare mean values across multiple treatment groups. In all cases, significance was assumed at a probability statistic of $<0.05$. All data are expressed throughout the text as mean \pm s.e.

\section{Reagents}

Unless otherwise specified, all reagents were purchased from Sigma.

\section{RESULTS}

\section{Acute Hepatic and Renal Dysfunction after Liver IR}

The survival rates for sham-operated animals and animals subjected to $60 \mathrm{~min}$ of liver ischemia and $24 \mathrm{~h}$ reperfusion were $100 \%(5 / 5)$ and $94 \%(15 / 16)$, respectively. Shamoperated C57BL/6 mice had normal plasma ALT and $\mathrm{Cr}$ at $4 \mathrm{~h}$ $(\mathrm{ALT}=61 \pm 12 \mathrm{mg} / 100 \mathrm{ml}, N=4$ and $\mathrm{Cr}=0.28 \pm 0.09 \mathrm{mg} /$ $100 \mathrm{ml}, N=4)$ and $24 \mathrm{~h}$ after surgery (ALT $=58 \pm 11 \mathrm{U} / \mathrm{l}$, $N=5$ and $\mathrm{Cr}=0.31 \pm 0.11 \mathrm{mg} / 100 \mathrm{ml}, N=5)$. However,
C57BL/6 mice subjected to liver IR developed severe liver dysfunction at 4 and $24 \mathrm{~h}$ after hepatic ischemic injury with significantly higher plasma ALT levels $(20097 \pm 1434 \mathrm{U} / \mathrm{l}$, $N=6, P<0.0001$ and $14560+2275 \mathrm{U} / \mathrm{l}, N=10, P<0.0001$, respectively, compared to sham-operated mice). Moreover, C57BL/6 mice subjected to liver IR also developed AKI with significant rises in plasma $\mathrm{Cr} 4 \mathrm{~h}(\mathrm{Cr}=0.60 \pm 0.09 \mathrm{mg} /$ $100 \mathrm{ml}, \quad N=6, \quad P<0.05 \quad$ vs sham) and $24 \mathrm{~h}$ $(\mathrm{Cr}=0.91 \pm 0.15 \mathrm{mg} / 100 \mathrm{ml}, N=10, P<0.05$ vs sham $)$ after liver IR. There was a direct relationship between the severity of liver dysfunction (ALT) and the degree of AKI (Cr) $24 \mathrm{~h}$ after IR $\left(P<0.0001\right.$ and $r^{2}=0.8925$; Figure 1). The BUN values also significantly increased in mice subjected to liver ischemia and $24 \mathrm{~h}$ reperfusion $(128 \pm 10 \mathrm{mg} / 100 \mathrm{ml}, N=10$, $P<0.0001)$ compared to the mice subjected to sham surgery $(12 \pm 2 \mathrm{mg} / 100 \mathrm{ml}, N=4)$.

\section{Hepatic IR Injury Results in Histological Changes in the Kidney}

As we observed previously, our model of $60 \mathrm{~min}$ partial hepatic IR injury produced moderate to severe liver necrosis $(76 \pm 9 \%, N=10)$ in all samples examined $24 \mathrm{~h}$ after IR 

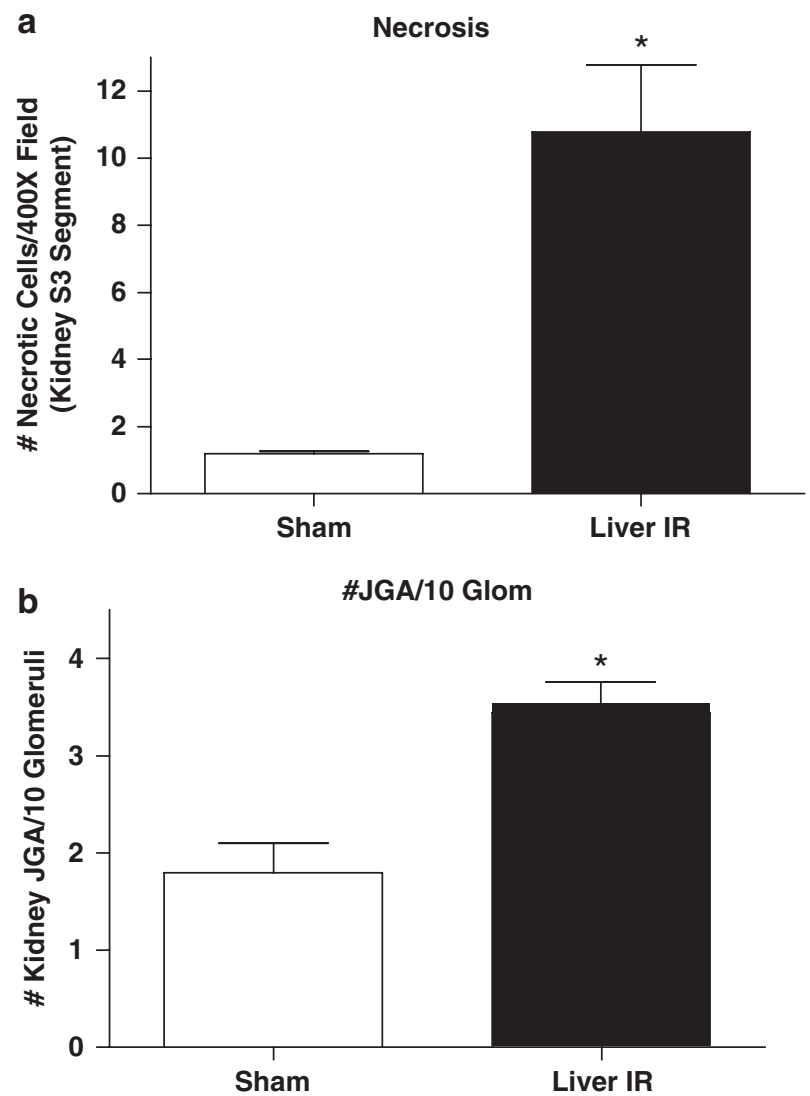

\# Cells/ JGA

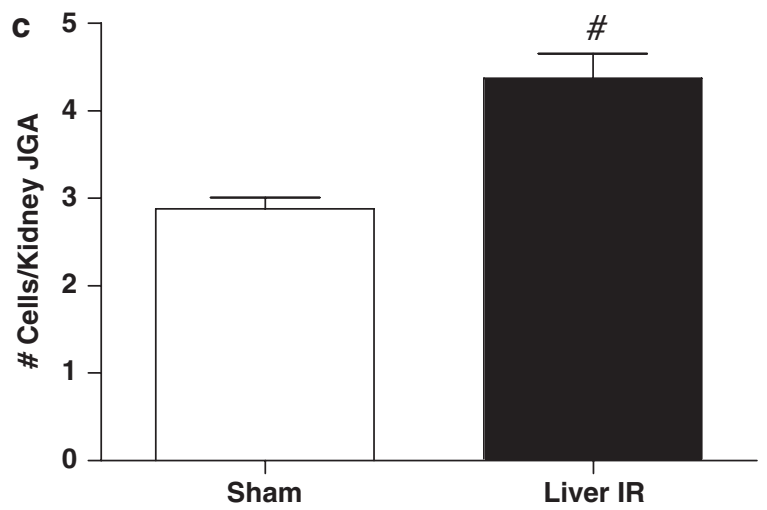

Figure 4 Renal histological assessment after liver IR in C57BL/6 mice. Mice were subjected to sham operation $(N=5)$ or to liver IR $(N=8)$. Twenty-four hours later, mice subjected to liver IR showed increased number of necrotic S3 proximal tubules per $400 \times$ field (a), increased number of juxtaglomerular apparatus (JGA) per 10 glomeruli counted (b) and increased number of cells per JGA (c). ${ }^{\star} P<0.01$ vs sham-operated mice. ${ }^{\#} P<0.05$ vs sham-operated mice. Data presented as mean \pm s.e.m.

with some sparing of the hepatocytes near the portal triad (Figure 2). We failed to detect liver necrosis in sham-operated animals. When we examined the kidneys from the mice subjected to liver IR, we observed multifocal acute tubular injury including individual cell necrosis involving the juxtamedullary proximal tubules of the S3 segment. In addition the cortical tubules exhibited focal tubular simplification, cytoplasmic vacuolization, dilated lumina and focal granular bile/heme casts, accompanied by mild interstitial edema. Endothelial apoptosis of peritubular capillaries was also visible in $\mathrm{H} \& \mathrm{E}$ sections as linear arrays of apoptotic bodies corresponding to interstitial capillary lining endothelium (Figure 3). Manual counting of cells in the S3 segment of proximal tubules showed significantly higher number of necrotic cells compared to the sham-operated mice (Figure 3). The number of glomeruli with detectable juxtaglomerular apparatus in H\&E sections and the number of cells per juxtaglomerular apparatus were both increased after liver IR, indicating hyperplasia of the juxtaglomerular apparatus (Figures 3 and 4).

\section{Hepatic IR Injury Increases Proinflammatory mRNA Expression in the Liver as well as in the Kidney}

With RT-PCR, we measured the expression of proinflammatory cytokine mRNAs in the liver and the kidney $4 \mathrm{~h}$ after liver IR. We showed previously that $60 \mathrm{~min}$ of hepatic ischemia and $4 \mathrm{~h}$ reperfusion resulted in significant upregulation of proinflammatory cytokine mRNAs in the liver compared to the sham-operated mice ${ }^{21}$ and again demonstrate this finding here (Figure $5 \mathrm{a}$ and $\mathrm{c}$ ). We now show that hepatic IR injury was associated with significantly increased proinflammatory mRNA expression (ICAM-1, TNF- $\alpha, \mathrm{KC}$, MCP-1 and MIP-2) in the kidney (Figure 5b and c) compared to the sham-operated mice.

\section{Hepatic IR Injury Increases Renal Neutrophil Infiltration $\mathbf{2 4} \mathrm{h}$ after IR Injury}

We showed previously that $60 \mathrm{~min}$ of hepatic ischemia and $24 \mathrm{~h}$ of reperfusion resulted in a significant influx of neutrophils into the liver compared to the sham-operated mice. ${ }^{21}$ Neutrophil infiltration was not detected in the kidneys from sham-operated mice, however, infiltration was easily visible in the kidneys from mice subjected to liver IR (Figure 6). Neutrophil infiltration was seen in both capillaries and in the interstitial space. Capillary infiltrations were seen in juxtamedullary cortex with extravasations occurring in small foci around peritubular capillaries. Interstitial infiltrations were more prominent involving the subcapsular and outer cortical regions.

\section{Hepatic IR Injury Increases Renal Apoptosis $\mathbf{2 4}$ h after IR Injury}

When the kidneys isolated from mice subjected to liver IR were examined for apoptosis, we observed significantly increased number of apoptotic nuclei (TUNEL-positive cells; Figure 7). TUNEL-positive cells were heavily localized to the interstitial capillary area rather than to the renal proximal tubule cells (cells typically showing apoptotic changes after renal IR). To clarify the location of TUNEL-positive cells, we double stained the kidney sections with hematoxylin and TUNEL stain. Figure 8 shows again that the TUNEL-positive cells are localized mostly in the interstitial perivascular area. 
a

GAPDH
ICAM1
KC
MCP1
MIP2
TNF- $\alpha$

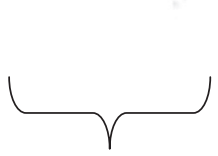

Liver

Expression After

Sham Surgery
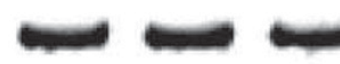

$\omega$
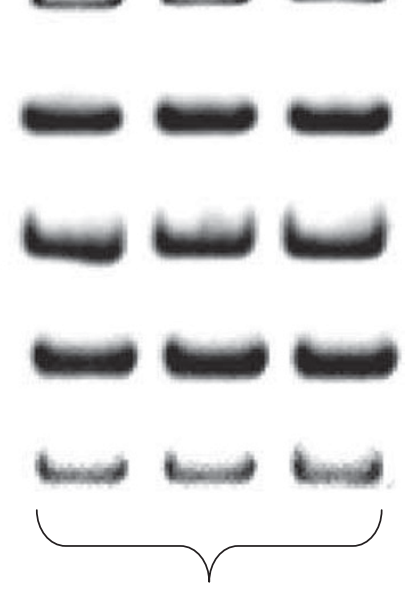

Liver

Expression

After

Liver IR

\section{b GAPDH}

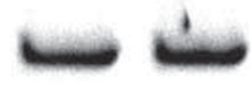

ICAM1
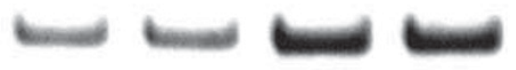

KC

MCP1

MIP2

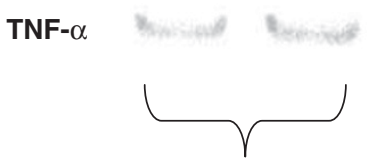

Kidney

Expression

After

Sham Surgery
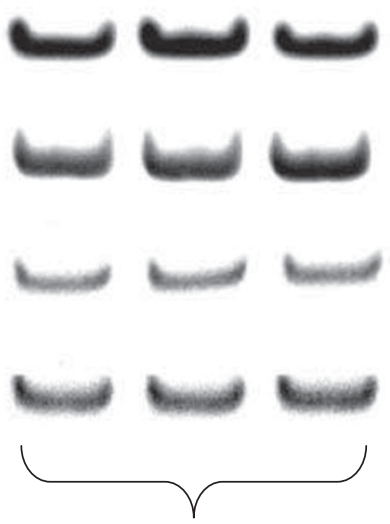

Kidney

Expression

After

Liver IR

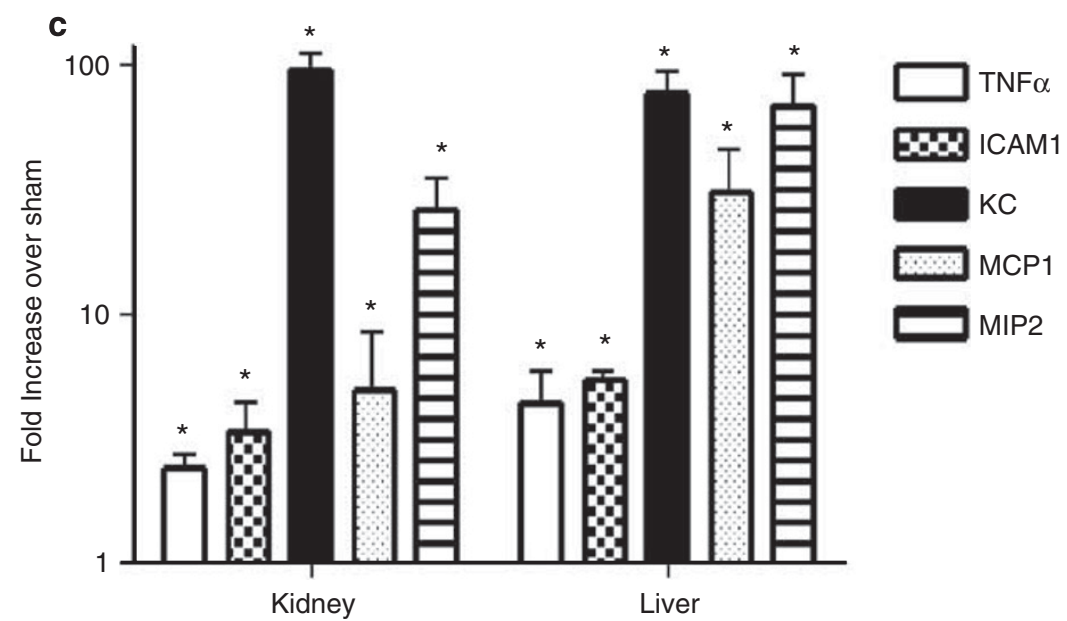

Figure 5 Representative gel images of semiquantitative RT-PCR of the pro-nflammatory markers ICAM-1, KC, MCP-1, MIP-2 and TNF- $\alpha$ from liver tissues (a) or from renal cortices (b) of C57BL/6 mice subjected to sham operation or to liver IR (60 min ischemia and $4 \mathrm{~h}$ reperfusion). Fold increases in proinflammatory mRNAs (in log10 scale) normalized to GAPDH from Q-RT-PCR reactions for each indicated mRNA ( $N=4$ for sham and $N=4$ for liver IR) are shown (c). ${ }^{*} P<0.05$ vs sham-operated mice. Error bars represent 1 s.e.m.

We further confirmed that the TUNEL-positive cells are interstitial capillary endothelial cells by staining parallel kidney sections with TUNEL and CD34 (an endothelial cell marker; Abcam Inc., Cambridge, MA, USA) and confirmed that TUNEL-positive cells also stained for CD34 (Figure 9; representative of four representative serial sections).

\section{Hepatic IR Disrupts Both Hepatocyte and Renal Tubule F-Actin Architecture}

Liver F-actin staining in sham-operated mice shows localization to the hepatocyte periphery and around the bile canaliculus. As expected, $60 \mathrm{~min}$ of liver ischemia and $24 \mathrm{~h}$ of reperfusion resulted in severe disruption of liver parenchymal F-actin compared to the sham-operated mice (Figure 10; representative of six experiments). Surprisingly, liver IR injury also resulted in a severe loss of F-actin in renal proximal tubules. In Figure 10, $24 \mathrm{~h}$ posthepatic IR induced disruptions of the F-actin cytoskeleton in renal proximal tubular epithelial cells are shown. C57BL/6 mice were subjected to sham surgery showed intense stain in the tubular epithelial and in the basal plasma membrane. In contrast, kidneys from mice subjected to liver IR showed loss of F-actin staining in the tubular epithelial cells. 

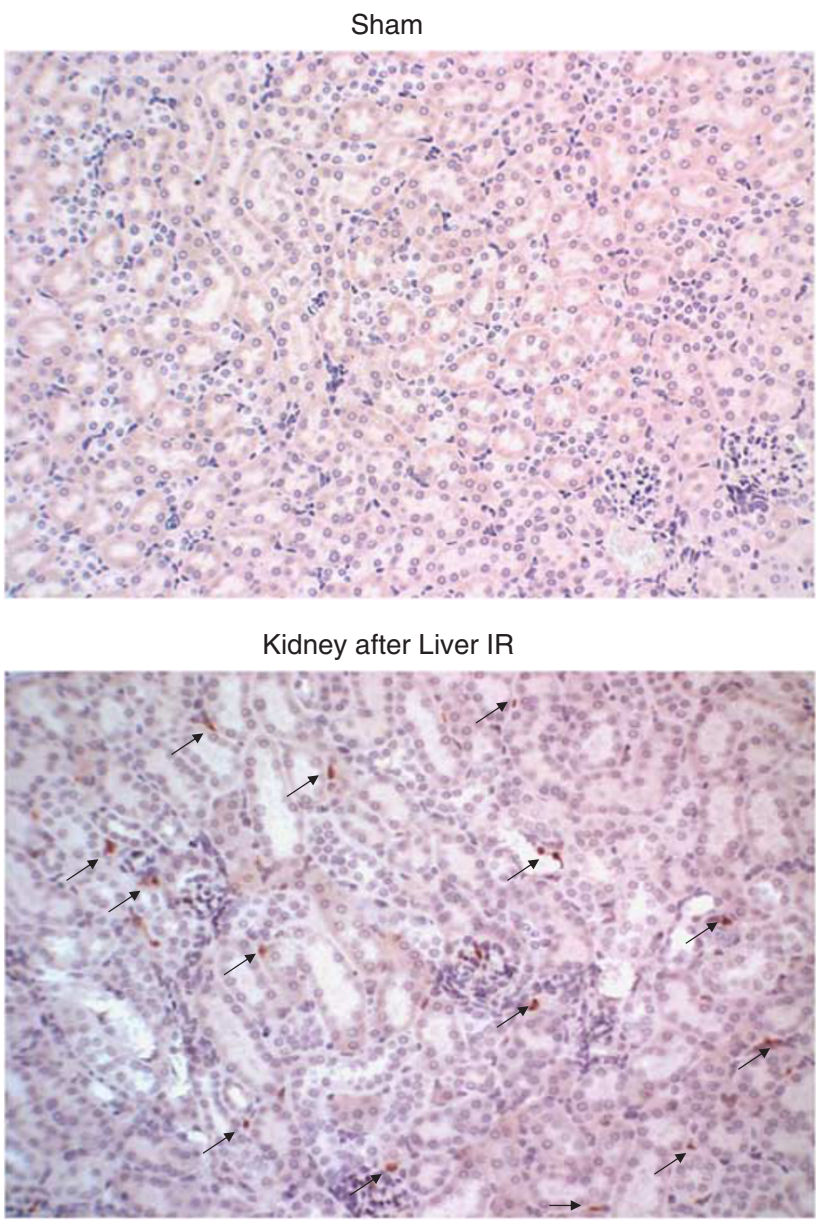

Figure 6 Representative photomicrographs $(100 \times)$ of four experiments of immunohistochemistry for neutrophil infiltration (arrows) in the outer medulla/inner cortex of the kidneys of C57BL/6 mice subjected to sham operation or to $60 \mathrm{~min}$ liver ischemia and $24 \mathrm{~h}$ reperfusion.

\section{Hepatic IR Increases Vascular Permeability in the Liver as well as in the Kidneys}

We measured liver and kidney vascular permeability after liver IR with EBD injection. EBD binds to plasma proteins and its appearance in extravascular tissues reflects an increase in vascular permeability. Analysis of EBD extravasations in sham-operated mice and mice subjected to liver IR is shown in Figure 11. Liver IR not only increased the EBD content in the liver $(337 \pm 43 \mu \mathrm{g} \mathrm{EBD/g}$ dry liver, $N=10)$ compared to sham-operated mice $(45 \pm 8 \mu \mathrm{g} \mathrm{EBD/g}$ dry liver, $N=6$, $P<0.001)$ but also increased the EBD content in the kidney as well (liver IR EBD: $77 \pm 6 \mu \mathrm{g} \mathrm{EBD} / \mathrm{g}$ dry kidney, $N=10 v \mathrm{~s}$ sham EBD: $46 \pm 9 \mu \mathrm{g}$ EBD/g dry kidney, $N=6, P<0.02$ ).

\section{DISCUSSION}

The major new finding of this study is that mice subjected to a clinically relevant model of liver IR injury developed severe AKI. Liver IR-induced AKI in mice shared similar histological changes observed in human AKI associated with liver failure
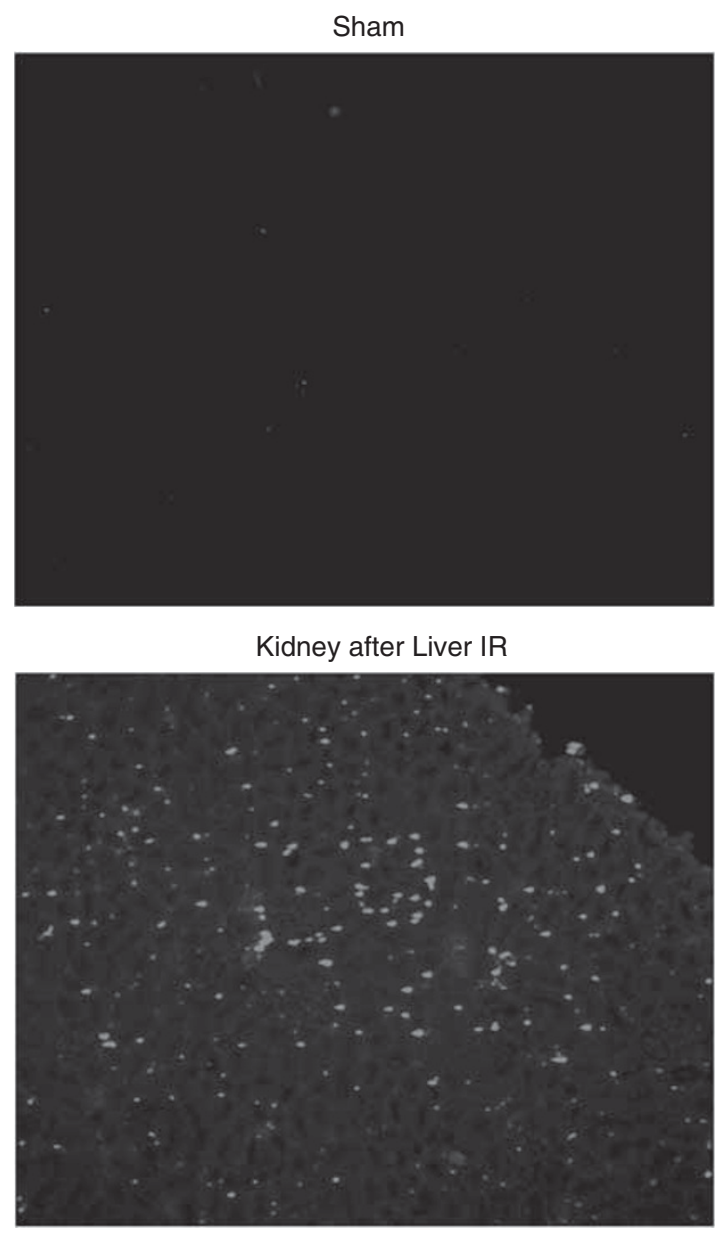

Figure 7 Representative fluorescence photomicrographs (of four experiments) of kidney sections illustrating apoptotic nuclei (terminal deoxynucleotidyl transferase biotin-dUTP nick-end labeling (TUNEL) fluorescence staining, $100 \times)$. C57BL/ 6 mice were subjected to shamoperation or to $60 \mathrm{~min}$ liver ischemia and $24 \mathrm{~h}$ reperfusion.

including JGA hyperplasia, renal tubule necrosis, proximal tubule simplification and vacuolization. In addition, we showed that mice with AKI displayed marked renal endothelial apoptosis and F-actin disruption in the kidney. Moreover, liver IR also caused renal cortical proinflammatory mRNA expression and infiltration of PMNs.

Hepatic IR induced ALF is a very common clinical problem and frequently leads to dysfunction of remote organs including the lung, heart and kidney. ${ }^{6,22-24}$ AKI associated with liver failure is a grave clinical problem with high mortality rate. In fact, the diagnosis of AKI in patients with liver failure implies a significant increase in mortality and morbidity. ${ }^{4,25-27}$ Supportive therapies for AKI associated with liver failure are limited to hydration, blood pressure support and short-term hemodialysis until renal function recovers. In fact, for hepatorenal syndrome (a type of AKI associated with ALF), liver transplantation is the only definitive treatment. ${ }^{6}$ Unfortunately, the pathogenesis of AKI associated with liver failure is poorly understood, largely due 
Sham
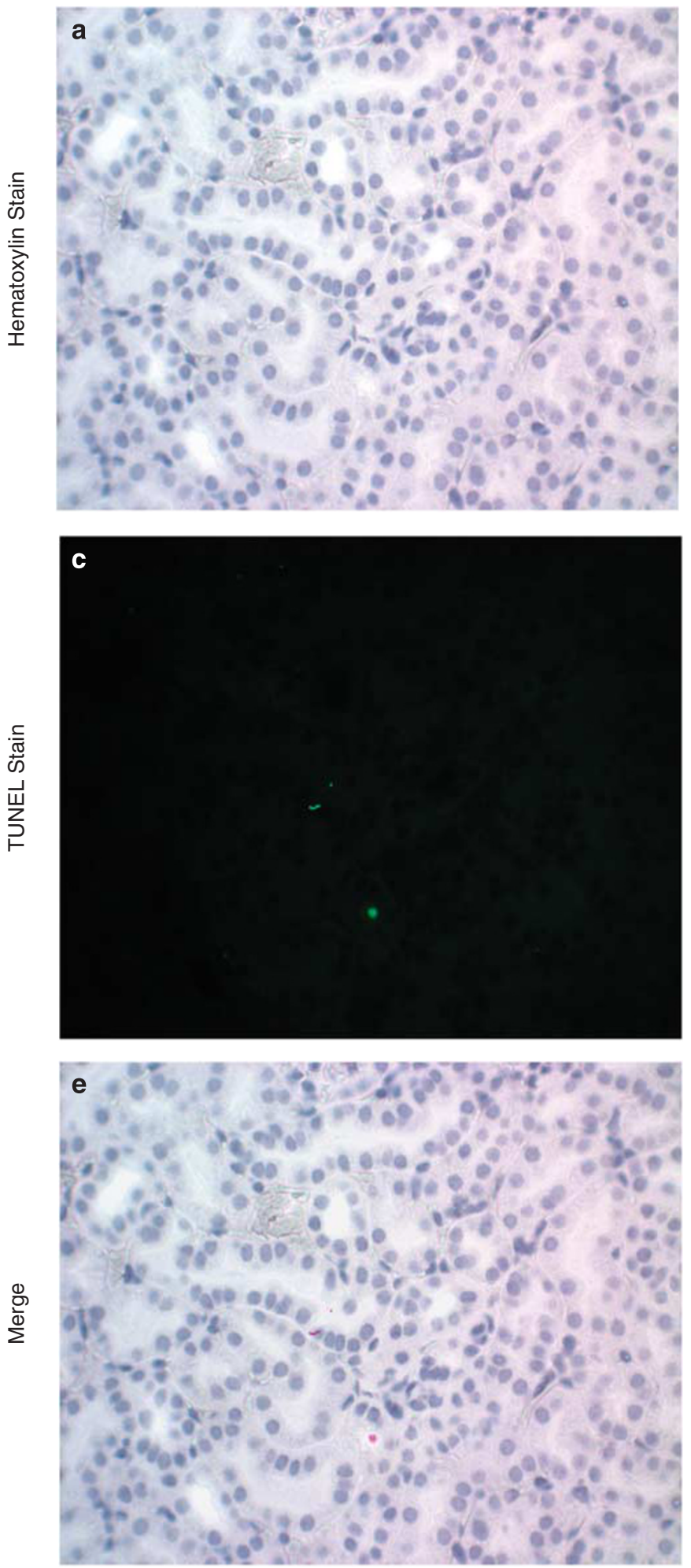

Liver IR
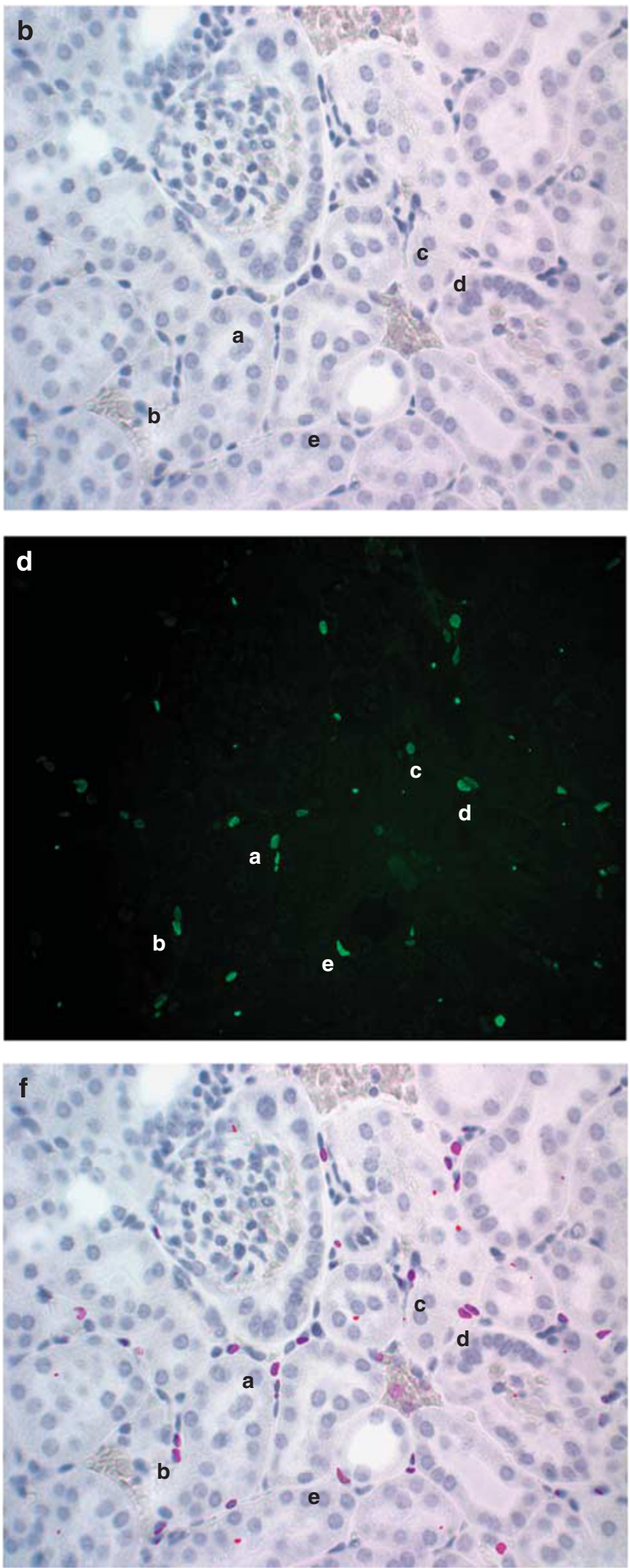

Figure 8 Renal endothelial cell apoptosis after liver IR. C57BL/6 mice were subjected to sham operation or to 60 min liver ischemia and $24 \mathrm{~h}$ reperfusion. Top panel: Hematoxylin stain $(400 \times)$ of kidneys from sham-operated mouse (a) or mouse subjected to liver IR (b). Middle panel: fluorescence photomicrographs of TUNEL staining from kidneys of mice subjected to sham operation (c) or to liver IR (d). Bottom panel: Merge of a and $\mathbf{c}$ (Sham, $\mathbf{e}$ ) revealed no evidence of apoptotic endothelial cells. In contrast, images from $\mathbf{b}$ and $\mathbf{d}$ (Liver IR) were merged (f) demonstrating apoptotic nuclei (represent in pink) within the renal endothelial cells in the kidney of the mouse subjected to liver IR. Some of the endothelial cells are labeled (a-e) showing overlapping nuclear stain and apoptotic stain. Representative of six experiments. 

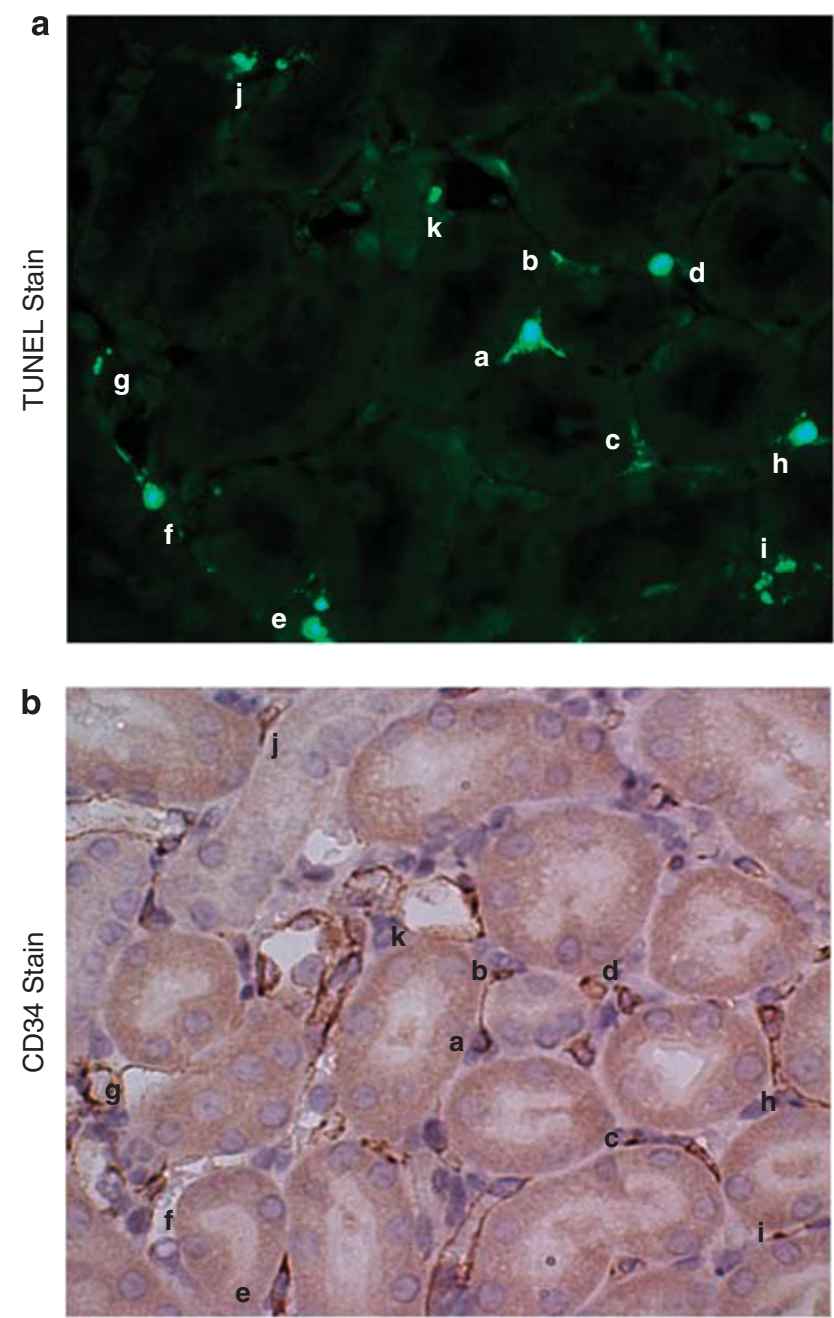

Figure 9 Further confirmation of renal endothelial cell apoptosis after liver IR. C57BL/6 mice were subjected to $60 \mathrm{~min}$ liver ischemia and $24 \mathrm{~h}$ reperfusion and serial kidney sections were stained with TUNEL (a) or with CD34 (an endothelial cell marker, b). TUNEL-positive endothelial cells are labeled (a-k). Representative of 4 serial sections stained.

to a lack of a reproducible and reliable animal model. A reproducible animal model would allow preclinical testing of therapeutic approaches that could lead to human therapy. In this study, we describe a model of AKI in mice induced with liver IR that is reproducible, rapid to develop (in less than $24 \mathrm{~h}$ ) and mimics the histological (renal tubular damage, apoptosis, necrosis and JGA hyperplasia) as well as biochemical (plasma creatinine, inflammatory markers) changes observed with human AKI associated with ALF. ${ }^{6}$

Although the pathophysiological and biochemical mechanisms of AKI associated with liver failure are not fully understood, the initiating event appears to be portal hypertension-induced splanchnic vasodilatation with subsequent intrarenal vasoconstriction. ${ }^{6,25,26}$ Patients with ALF develop hypotension secondary to splanchnic and peripheral vasodilation and hypovolemia. ${ }^{6}$ The renin-angio- tensin system is activated due to a reduced systemic blood pressure and splanchnic vasodilation. ${ }^{6,7}$ Upregulation of renin-angiotensin system leads to severe reduction glomerular filtration rate, urinary sodium excretion and free water excretion. It has been proposed that intense intra-renal ischemia subsequent to renin-angiotensin activation leads to renal tubular necrosis and renal dysfunction. In this study, we show significant hyperplasia of juxtaglomerular apparatus with increased cellularity in mice subjected to liver IR. These changes are similar to the changes seen in human AKI associated with ALF reflecting intense upregulation of the renin-angiotensin system. ${ }^{6,25}$ We also show several hallmark signs of renal damage due to intense intrarenal vasoconstriction including renal tubular necrosis, tubular simplification and vacuolization.

However, other mechanisms may play important roles in the pathogenesis of renal dysfunction with ALF. Systemic inflammatory response after liver IR may induce renal injury. ${ }^{6,22}$ After liver IR injury, circulating proinflammatory cytokines and transcription factors including TNF- $\alpha$ and HMGB1 increase significantly. ${ }^{23,28,29}$ Release of proinflammatory cytokines such as TNF- $\alpha$ and HMGB1 from the liver may promote inflammatory changes in the kidney after liver IR. ${ }^{22,28,29}$ These proinflammatory factors can upregulate endothelial adhesion molecules in distant organs including the kidney. Upregulation of renal endothelial adhesion molecules including E-selectin, P-selectin and ICAM-1 promotes leukocyte recruitment and extravasations to the renal interstitial space. ${ }^{30,31}$ In addition, circulating bile acids, endotoxin and circulating immune complexes may contribute to the development of AKI. ${ }^{6}$ Combined, these contributing factors may potentiate systemic inflammation leading to renal injury and renal PMN infiltration.

The endothelial barrier serves to protect against AKI by regulating leukocyte recruitment to the areas of injury. ${ }^{1,30}$ In this study, we were surprised to observe a marked endothelial cell apoptosis in the kidney after liver IR (Figures 7 and 8). Apoptosis is an important contributor in the development of renal failure. ${ }^{32,33}$ Apoptotic cell death represents the execution of an ATP-dependent death program often initiated by death ligand/death receptor interactions, such as Fas ligand with Fas, which leads to a caspase activation and cleavage of nuclear materials such as DNA and PARP. ${ }^{34,35}$ After liver IR, we show that interstitial capillary endothelial cell apoptosis in the kidney was much more prominent than the proximal tubule cell apoptosis. This is in contrast to the findings after renal IR where proximal tubule cell apoptosis predominates. Endothelial cell death due to apoptosis would impair defense against leukocyte invasion into the kidney leading to a further exacerbation of renal injury. The results of our study suggest that reducing endothelial cell death may limit renal injury associated with ALF.

In this study, we demonstrate not only significant endothelial cell apoptosis but also recruitment of PMNs to the kidney after liver IR. Neutrophils are activated during and after liver ische- 
a

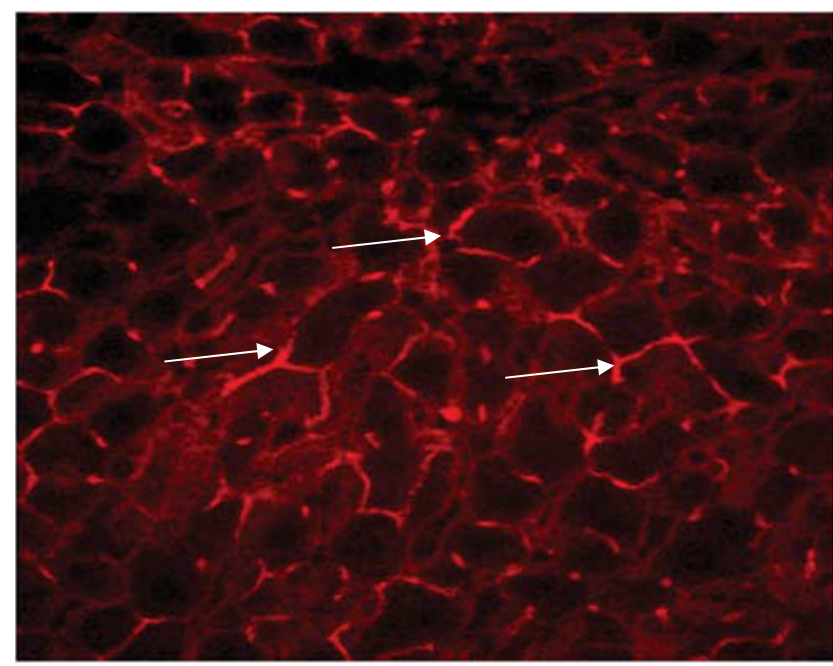

C

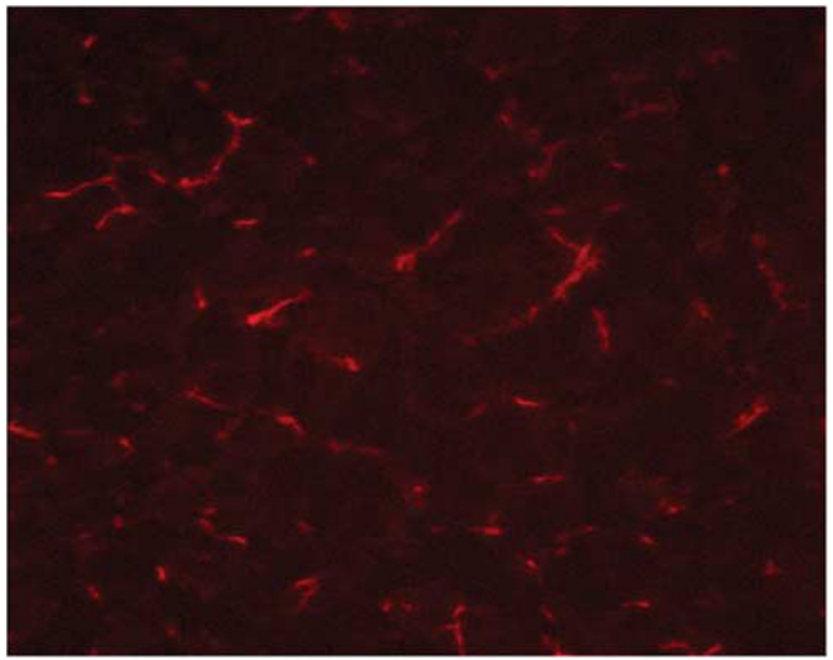

b

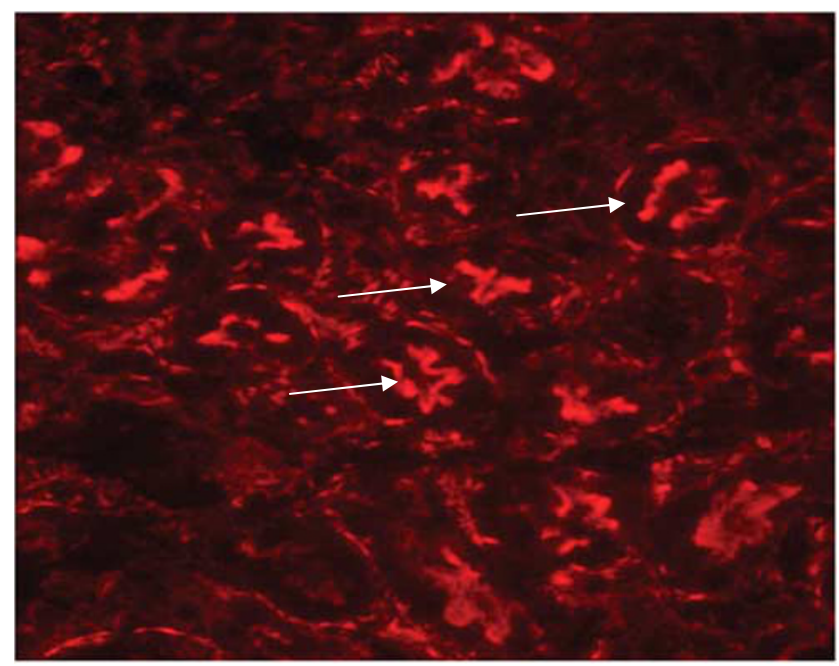

d

Kidney after Liver IR

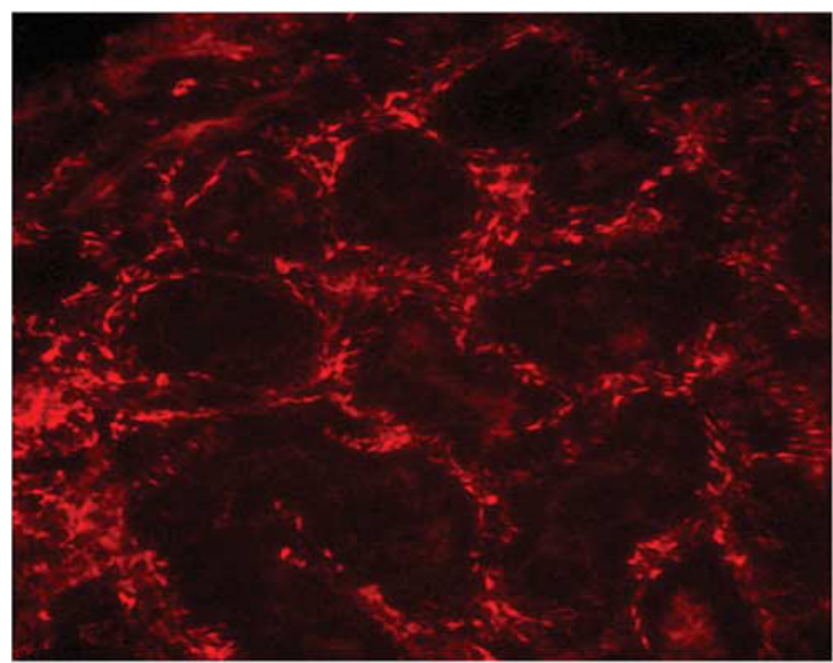

Figure 10 Representative fluorescent photomicrographs of phalloidin labeling to visualize F-actin in the liver ( $\mathbf{a}$ and $\mathbf{c}$ ) and in the renal proximal tubules (b and d) from C57BL/6 mice subjected to sham operation ( $\mathbf{a}$ and $\mathbf{b}$ ) or to $60 \mathrm{~min}$ liver ischemia and $24 \mathrm{~h}$ reperfusion (c and $\mathbf{d}$ ). Representative of six independent experiments. Arrows represent some of the intact F-actin structure in the liver or in the renal proximal tubular epithelial cells.

mia and activated neutrophils attach to and then transverse the renal capillary endothelium into the subendothelial space, where they release enzymes and cytokines, causing direct renal injury and the recruitment of other injurious cells, such as monocytes and macrophages. ${ }^{36,37}$ Weakened endothelial defenses after liver IR may potentiate the PMN infiltration and conversely, increasing the survival of endothelial cells after liver IR may limit PMN infiltration into the kidney and improve renal function. Future studies with endothelial stabilizing agents (such as activated protein C or sphingosine-1-phosphate) will determine whether protecting endothelial integrity will reduce renal injury after liver IR injury.

IR injury in vivo results in degradation of F-actin. Breakdown of F-actin contributes to the pathophysiology of organ dysfunction after IR injury or sepsis. ${ }^{38}$ Whereas we were not surprised to see changes in liver F-actin content after liver IR (Figure 9), we were surprised to demonstrate that renal F-actin breakdown occurs with liver IR. Actin cytoskeletal damage contributes significantly to the development of AKI. ${ }^{38,39}$ Moreover, F-actin disruption promotes apoptosis in several cell lines. ${ }^{40}$ Therefore, loss of actin cytoskeleton may have contributed to the development of renal tubular and endothelial apoptosis after liver IR.

We demonstrate in this study that plasma ALT and Cr have a direct and linear relationship: mice with higher ALT showed increased renal dysfunction after liver IR. However, we also noted that the degree of renal dysfunction was mild when the plasma ALT levels were below $10000 \mathrm{U} / \mathrm{l}$. Behrends et $a l^{8}$ 

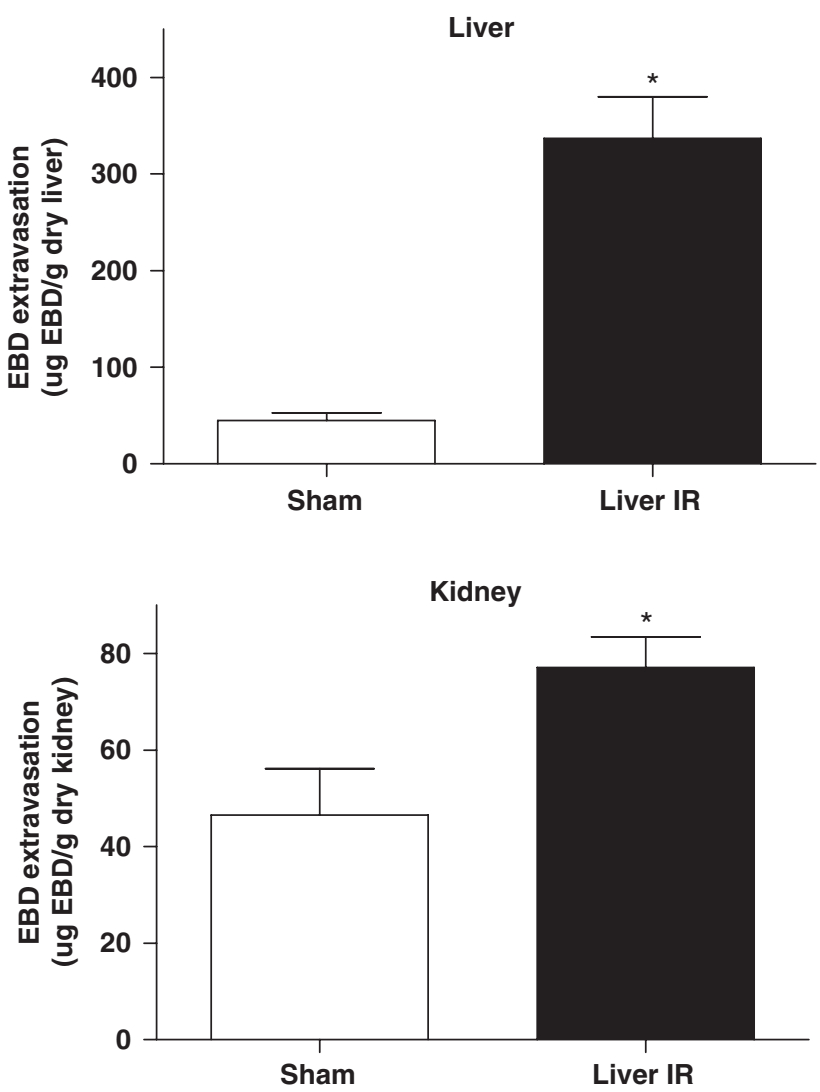

Figure 11 Liver IR increases vascular permeability in the liver as well as in the kidney. C57BL/6 mice were subjected to sham operation $(N=6)$ or to 60 min liver ischemia and $24 \mathrm{~h}$ reperfusion $(N=10)$. EBD was extracted in formamide and the amount of extravasated EBD concentration in liver and kidney was calculated against a standard curve. ${ }^{\star} P<0.05$ vs sham-operated mice. Error bars represent 1 s.e.m.

recently studied the renal dysfunction after extensive liver IR injury in rats. In their study, rats subjected to $75 \mathrm{~min}$ of partial liver IR developed acute liver dysfunction at $24 \mathrm{~h}$. However, the degree of renal dysfunction in their rat model was mild with modest increases in plasma creatinine. They also noted upregulation of ICAM-1 mRNA expression over control animals but no changes in renal MCP-1, MIP2 and iNOS expression were noted. Correspondingly, the kidneys from rats subjected to liver IR showed little morphological damage and they failed to see increases in apoptosis (caspase-3) and neutrophil infiltration (myeloperoxidase activity). Their study confirms previous observations in rats that renal dysfunction was mild with little or no histological changes after liver IR. ${ }^{9,41}$ Polat et $a l^{9}$ also reported that $45 \mathrm{~min}$ of liver ischemia resulted in mild renal dysfunction without detectable changes in renal morphology. The reason for this discrepancy between our mouse model and the previous rat model is unclear. However, in the study by Behrends et al, ${ }^{8}$ plasma ALT rose only to $\sim 6800 \mathrm{U} / \mathrm{l}$ whereas in our mouse model, the plasma ALT rose much higher $(\sim 15-20000 \mathrm{U} / \mathrm{l})$. Longer liver ischemic period (eg, $90 \mathrm{~min}$ ) in a rat is usually lethal (unpublished observations). Therefore, it appears that the murine model is better suited as model of liver failure-induced AKI than the rat model.

Some investigators utilized $\mathrm{CCl}_{4}$-induced cirrhosis as a model of liver failure-induced renal injury. ${ }^{7}$ Our model has several advantages over this model as our model is more clinically relevant, does not require administration of a tubular toxin and results in rapid and severe AKI. The $\mathrm{CCl}_{4}$ injection model is limited by the chronic nature of the protocol requiring several weeks (whereas human AKI can develop in less than a week). Moreover, full-blown renal dysfunction does not usually occur until day 3 with the $\mathrm{CCl}_{4}$ model whereas we can produce liver failure-induced AKI in less than $24 \mathrm{~h}$.

To our knowledge, this is the first study utilizing mice to develop a model of AKI after acute liver dysfunction. Our model of AKI after liver IR closely mimics human AKI associated with ALF in terms of severity and the acute nature of renal dysfunction as well as similarities in histological changes. Utilization of mice has further advantages in that genetically modified mice are available to complement pharmacological approaches in studying the signaling mechanisms as well as examining potential therapies for AKI associated with ALF.

Serum creatinine is the most commonly used clinical indicator of glomerular filtration rate but its reliability as a measurement of glomerular filtration rate may be limited by several factors after acute liver injury. One of the main functional consequences of acute liver injury is a dramatic reduction in serum protein level, which influences the intravascular volume and glomerular filtration rate. Acute liver injury actually can lead to low serum creatinine due to decreased hepatic conversion of creatine to creatinine, decreased dietary protein intake and increased renal tubular secretion of creatinine. The increased fraction of creatinine excretion by tubular secretion in the setting low GFR also diminishes the reliability of creatinine as a marker of renal dysfunction. Consequently, the plasma creatinine values reported in this study in mice $(0.91 \pm 0.15 \mathrm{mg} / 100 \mathrm{ml})$ may actually underestimate the degree of AKI associated with liver IR. Our measurements of plasma BUN correlated less well with renal function, probably because of interference with the urea cycle and hepatic metabolism after liver IR.

In summary, we have developed a novel murine model of AKI after liver IR, which closely approximates the human disease, characterized by renal tubular necrosis, endothelial cell apoptosis, PMN infiltration and JGA hyperplasia. Our model should provide a useful experimental context to delineate the mechanisms of AKI after liver IR and evaluate potential pharmacological therapies. Our study is the first to characterize the histological changes in detail and to demonstrate marked endothelial apoptosis and F-actin destruction in AKI associated with acute liver injury. It remains to be determined in future studies whether stabilization of endothelial cells would protect against AKI after liver IR injury. 


\section{ACKNOWLEDGEMENT}

This work was supported by National Institute of Health Grant RO1 DK-58547.

\section{CONFLICT OF INTEREST}

We declare that no financial conflict of interest exists for each author.

1. Teoh NC, Farrell GC. Hepatic ischemia reperfusion injury: pathogenic mechanisms and basis for hepatoprotection. J Gastroenterol Hepatol 2003;18:891-902.

2. Serracino-Inglott $F$, Habib NA, Mathie RT. Hepatic ischemia-reperfusion injury. Am J Surg 2001;181:160-166.

3. Fondevila C, Busuttil RW, Kupiec-Weglinski JW. Hepatic ischemia/ reperfusion injury - a fresh look. Exp Mol Pathol 2003;74:86-93.

4. Betrosian $A P$, Agarwal $B$, Douzinas EE. Acute renal dysfunction in liver diseases. World J Gastroenterol 2007;13:5552-5559.

5. Arroyo V, Fernandez J, Gines P. Pathogenesis and treatment of hepatorenal syndrome. Semin Liver Dis 2008;28:81-95.

6. Davis $\mathrm{CL}$, Gonwa TA, Wilkinson AH. Pathophysiology of renal disease associated with liver disorders: implications for liver transplantation. Part I. Liver Transpl 2002;8:91-109.

7. Rivera-Huizar S, Rincon-Sanchez AR, Covarrubias-Pinedo A, et al. Renal dysfunction as a consequence of acute liver damage by bile duct ligation in cirrhotic rats. Exp Toxicol Pathol 2006;58:185-195.

8. Behrends $M$, Hirose R, Park $Y H$, et al. Remote renal injury following partial hepatic ischemia/reperfusion injury in rats. J Gastrointest Surg 2008;12:490-495.

9. Polat C, Tokyol C, Kahraman A, et al. The effects of desferrioxamine and quercetin on hepatic ischemia-reperfusion induced renal disturbance. Prostaglandins Leukot Essent Fatty Acids 2006;74:379-383.

10. Lappas CM, Day YJ, Marshall MA, et al. Adenosine A2A receptor activation reduces hepatic ischemia reperfusion injury by inhibiting CD1d-dependent NKT cell activation. J Exp Med 2006;203:2639-2648.

11. Day $Y J$, Marshall MA, Huang $L$, et al. Protection from ischemic liver injury by activation of $A 2 A$ adenosine receptors during reperfusion: inhibition of chemokine induction. Am J Physiol Gastrointest Liver Physiol 2004;286:G285-G293.

12. SLOT C. Plasma creatinine determination. A new and specific Jaffe reaction method. Scand J Clin Lab Invest 1965;17:381-387.

13. Joo JD, Kim M, Horst $P$, et al. Acute and delayed renal protection against renal ischemia and reperfusion injury with $A 1$ adenosine receptors. Am J Physiol Renal Physiol 2007;293:F1847-F1857.

14. Kim $M$, Kim $M$, Kim N, et al. Isoflurane mediates protection from renal ischemia-reperfusion injury via sphingosine kinase and sphingosine-1phosphate-dependent pathways. Am J Physiol Renal Physiol 2007;293:F1827-F1835.

15. Lee HT, Gallos G, Nasr SH, et al. A1 adenosine receptor activation inhibits inflammation, necrosis, and apoptosis after renal ischemiareperfusion injury in mice. J Am Soc Nephrol 2004;15:102-111.

16. Gallos G, Ruyle TD, Emala CW, et al. A1 adenosine receptor knockout mice exhibit increased mortality, renal dysfunction, and hepatic injury in murine septic peritonitis. Am J Physiol Renal Physiol 2005;289:F369-F376.

17. Gallos $\mathrm{G}$, Jones $\mathrm{DR}$, Nasr $\mathrm{SH}$, et al. Local anesthetics reduce mortality and protect against renal and hepatic dysfunction in murine septic peritonitis. Anesthesiology 2004;101:902-911.

18. Molitoris BA. Putting the actin cytoskeleton into perspective: pathophysiology of ischemic alterations. Am J Physiol 1997;272: F430-F433.
19. Molitoris BA. Ischemia-induced loss of epithelial polarity: potential role of the actin cytoskeleton. Am J Physiol 1991;260:F769-F778.

20. Awad AS, Ye H, Huang L, et al. Selective sphingosine 1-phosphate 1 receptor activation reduces ischemia-reperfusion injury in mouse kidney. Am J Physiol Renal Physiol 2006;290:F1516-F1524.

21. Kim J, Kim M, Song JH, et al. Endogenous A1 adenosine receptors protect against hepatic ischemia reperfusion injury in mice. Liver Transpl 2008;14:845-854.

22. Tanaka $Y$, Maher JM, Chen $C$, et al. Hepatic ischemia-reperfusion induces renal heme oxygenase-1 via NF-E2-related factor 2 in rats and mice. Mol Pharmacol 2007;71:817-825.

23. Wanner GA, Ertel $W$, Muller $P$, et al. Liver ischemia and reperfusion induces a systemic inflammatory response through Kupffer cell activation. Shock 1996:5:34-40.

24. Weinbroum AA, Hochhauser E, Rudick V, et al. Direct induction of acute lung and myocardial dysfunction by liver ischemia and reperfusion. J Trauma 1997;43:627-633.

25. Wadei HM, Mai ML, Ahsan N, et al. Hepatorenal syndrome: pathophysiology and management. Clin J Am Soc Nephrol 2006;1:1066-1079.

26. Schepke M. Hepatorenal syndrome: current diagnostic and therapeutic concepts. Nephrol Dial Transplant 2007;22(Suppl 8):viii2-viii4.

27. Genzini T, Torricelli FC. Hepatorenal syndrome: an update. Sao Paulo Med J 2007;125:50-56.

28. Tsung A, Hoffman RA, Izuishi $K$, et al. Hepatic ischemia/reperfusion injury involves functional TLR4 signaling in nonparenchymal cells. J Immunol 2005;175:7661-7668.

29. Levy RM, Mollen KP, Prince JM, et al. Systemic inflammation and remote organ injury following trauma require HMGB1. Am J Physiol Regul Integr Comp Physiol 2007;293:R1538-R1544.

30. Sutton TA, Mang HE, Campos SB, et al. Injury of the renal microvascular endothelium alters barrier function after ischemia. Am J Physiol Renal Physiol 2003;285:F191-F198.

31. Molitoris BA, Sandoval R, Sutton TA. Endothelial injury and dysfunction in ischemic acute renal failure. Crit Care Med 2002:30:5235-\$240.

32. Lieberthal W, Koh JS, Levine JS. Necrosis and apoptosis in acute renal failure. Semin Nephrol 1998;18:505-518.

33. Daemen MA, de Vries B, Buurman WA. Apoptosis and inflammation in renal reperfusion injury. Transplantation 2002;73:1693-1700.

34. Ueda N, Kaushal GP, Shah SV. Apoptotic mechanisms in acute renal failure. Am J Med 2000;108:403-415.

35. Lee HT, Kim M, Jan $M$, et al. Renal tubule necrosis and apoptosis modulation by $\mathrm{A} 1$ adenosine receptor expression. Kidney Int 2007;71:1249-1261.

36. Okusa MD. The inflammatory cascade in acute ischemic renal failure. Nephron 2002;90:133-138.

37. Klausner JM, Paterson IS, Goldman G, et al. Postischemic renal injury is mediated by neutrophils and leukotrienes. Am J Physiol 1989;256:F794-F802.

38. Molitoris BA. Actin cytoskeleton in ischemic acute renal failure. Kidney Int 2004;66:871-883.

39. Kellerman PS, Norenberg SL, Jones GM. Early recovery of the actin cytoskeleton during renal ischemic injury in vivo. Am J Kidney Dis 1996;27:709-714.

40. White SR, Williams P, Wojcik KR, et al. Initiation of apoptosis by actin cytoskeletal derangement in human airway epithelial cells. Am J Respir Cell Mol Biol 2001;24:282-294.

41. Kudo Y, Egashira T, Takayama F, et al. Investigation of the renal injury caused by liver ischemia-reperfusion in rats. Arch Toxicol 1993;67:502-509. 